User Knowledge Creation in Universal Design processes

Peer-reviewed author version

IELEGEMS, Elke; HERSSENS, Jasmien \& VANRIE, Jan (2016) User Knowledge

Creation in Universal Design processes. In: Di Bucchianico, Giuseppe; Kercher, Pete (Ed.). Advances in Design for Inclusion: Proceedings of the AHFE 2016 International Conference on Design for Inclusion, July 27-31, 2016, Walt Disney World®, Florida, USA, Springer International Publishing,p. 141-154.

DOI: $10.1007 / 978-3-319-41962-6 \_13$

Handle: http://hdl.handle.net/1942/22036 


\title{
User Knowledge Creation in Universal Design Processes
}

\author{
Elke Ielegems ${ }^{1}$, Jasmien Herssens ${ }^{1}$, Jan Vanrie ${ }^{1}$, \\ ${ }^{1}$ Hasselt University, Faculty of Architecture and Arts, Hasselt Belgium \\ Elke.Ielegems@uhasselt.be,Jasmien.Herssens@uhasselt.be,Jan.Vanrie@uhasselt.be
}

\begin{abstract}
Besides the need for designers to build a strong body of user knowledge within the domain of Universal Design (UD), linking knowledge about user needs and design practice is fundamental for increasing its uptake. Designers often experience difficulties when transferring user needs into inclusive design solutions. The tacit nature of user needs considerably complicates this transfer. Therefore, this paper examines how designers may create and apply knowledge on UD. Concepts from Knowledge Management are used to shed new light on designers' knowledge creation process about user needs. By relating UD processes to Nonaka's SECI model, an analytical framework is proposed in which four modes of developing knowledge enable us to analyse the continuous dialogue between tacit and explicit knowledge from user to designer. As such, this paper explores to which extent the SECI model offers interesting insights into designers' knowledge creation process on user needs.
\end{abstract}

Keywords: Communication $\cdot$ tacit and explicit knowledge $\cdot$ SECI model knowledge creation $\cdot$ architecture $\cdot$ design process $\cdot$ Universal Design $\cdot$ Inclusive Design · Design for All

The final publication is available at Springer via http://dx.doi.org/10.1007/9783-319-41962-6

\section{Introduction}

Theoretical and empirical research on Universal Design (UD) is exponentially growing. Demographic changes and design innovation require an increasing amount of knowledge about user needs. According to Dong and colleagues [1], understanding end-users from different perspectives is one of two research areas within the user knowledge base of UD. The other area aims at understanding the information needs of knowledge users promoting or creating UD solutions, such as designers, policy makers, etc. However, in design practice there is still a gap between these two areas: when translating user needs into design solutions throughout a UD process, in many cases designers' existing design knowledge does not sufficiently include the aspect of user needs [2]. In other words, there is a gap between designers' knowledge about user needs and their design knowledge. This paper therefore reflects on different modes of creating knowledge about user needs in a UD process. 
Various scholars have already suggested that concepts on knowledge creation in business can provide interesting links with creative disciplines, such as design or art [e.g. 3, 4, 5, 6]. By introducing concepts from Knowledge Management (KM), we want to propose an analytical framework to investigate designers' actual knowledge creation in the context of UD. Inspired by Nonaka's knowledge creation theory [7], this paper adapts the SECI model to study how designers' knowledge creation process on user needs may affect UD processes. Although the concepts discussed in this paper are applicable and relevant to various design domains, we focus on the built environment.

The first section of this paper defines the concept of user needs and knowledge creation in the context of UD. Both sections two and three elaborate on Nonaka's SECI model in order to link user knowledge to design practice as a continuous dialogue between tacit and explicit knowledge.

\section{User Needs and Knowledge in a Universal Design Context}

\subsection{Translating User Needs into Design Solutions throughout Universal Designing}

Universal Design (UD), Inclusive Design (ID) and Design for All (DfA) are synonyms all aiming "at elegant, usable and sustainable design solutions for products, services and environments, so that users are supported in their actions and experiences and that the design can be used to the greatest extent possible by everyone" [8]. UD is considered as a design strategy throughout the design stages rather than an objective or end-result $[9,10]$. This way, the process of Universal Designing is emphasised as a non-stop design and building process with continuous user feedback [11]. Importantly, when applying UD as a design strategy, it is generally considered fundamental that user needs are taken into account in the design process from the earliest stages of designing [e.g. 10, 12,13]. Choices made at the beginning may have significant consequences on possibilities later on in the process [12, 14].

Thus, how do architects acquire knowledge about user needs? Kirkeby [12] specifies that architects generally use a rich variety of different sources throughout the design process, ranging from rule-based knowledge and facts to good examples and concepts. User needs can be transferred to designers through direct user involvement, such as focus groups and workshops, or through indirect involvement utilising, for example, academic papers and checklists. Each of these approaches has advantages as well as limitations and it is important that designers select methods fitting their own design approach. Moreover, the chosen methods need to provide designers with the expected knowledge outcome in order to be usable throughout the design process [15]. First, however, we need to address the epistemological and ontological foundations of this question: how do we define knowledge and how do we interpret the concept of user needs? 


\subsection{Defining User Knowledge Creation for UD}

In this paper, the term knowledge is deliberately used in contrast to information or data. Although the terms information and knowledge are often intertwined, a clear distinction is visible [7]. Bender and Fish [16] schematically visualised knowledge in relation to data, information and expertise in a hierarchical structure. Data are raw numbers or facts with no context or judgement attached to it. For example, minimum sizes for a toilet usable by all can be considered as raw user data. This raw material becomes information when it is given meaning and purpose [16]. In contrast to data, information may convince, describe, challenge, move, etc. If the minimum sizes of the toilet would be illustrated in a sketch showing a possible toilet setting (such as in an educational flyer), this may be considered as information about user needs. Next, information can turn into 'knowledge' when it is interpreted and related to a context by its holder [7]. Knowledge will be created when integrating information with what we already know, or in other words: "It is information interpreted by the individual and applied to the purpose for which it is needed" [17]. For example, when a spatial expert and a layperson are reading the same book, different knowledge may be generated. Although the original information is similar, their background, experience and interpretation would be different [18].

Knowledge is understood in a broad sense of the word, including not only facts and rule-based knowledge, but also intuitive and experience-based kinds of knowledge that can generate true understanding of user needs. Finally, gaining 'expertise' is placed on top of the hierarchy. The difference between knowledge and expertise can be found in the depth of knowledge: Knowledge becomes expertise in a specific field when it is enriched by long-time experience, education and training [19].

In general, when relating these concepts to the field of UD, merely collecting data on user needs is not enough to cope with the challenges of designing inclusive environments. It does not give sufficient meaning to truly understand the lives of real people [20]. Designers need to be able to actively interpret this user data or information in order to gain personal knowledge that can be integrated in specific design situations [21]. We can illustrate this with our example of the toilet: When designers have sufficient expertise and truly understand why some users need extra space and how they make use of the toilet settings, they are able to effectively transfer this knowledge into other toilet designs suited for all. However, when designers do not fully comprehend the underlying principles, they might design a toilet, which is still useless for some users despite having applied the right minimum measurements.

Thus, in addition to user data and information, designers require knowledge to appropriately address user needs in UD. This way, they can understand the underlying reasoning and qualitatively embed the acquired user information in a descriptive way in daily design practice [22]: "Knowledge on people is essential in order to come up with informed and inspired design interventions" [23].

\subsection{The Tacit Nature of User Needs}

Having discussed the concept of user knowledge creation, we now focus on the concept of user needs. In this paper, the term user needs is to be interpreted in its broadest sense. It concerns all aspects that are potentially required for users to fully develop 
themselves in the built environment. These needs do not only address primary physical needs (e.g. accessibility), but also other needs, such as social needs or needs to enable personal growth [24]. User needs are not perceived as the needs of one person, but as those of the widest diversity of people, with and without disabilities.

Having identified user needs, it should be noted that only a relatively small percentage of user needs exists out of explicit knowledge that is easily articulated and written down in checklists, guidelines or regulations. The main body of user needs is tacit by nature. Whereas explicit knowledge is easy to verbalise, tacit knowledge is much more difficult to capture or communicate [7]. For example, you can easily describe how your bicycle looks like, but it is much more difficult to explain how to ride that bicycle. The former is defined as explicit knowledge, whereas the latter is tacit knowledge. Tacit knowledge is more intuitive, unarticulated by nature [25] and deeply rooted in our actions, crafts and skills [7]. Polanyi [25] accurately phrases tacit knowledge as follows: "We know more than we can tell". The knowing is in the action itself by "intelligently doing something in an intuitive manner" [26].

O'Shea [27] confirms the difficulty within the domain of UD to express all tacit, hard to describe qualities of building experience, which are nevertheless of fundamental importance to designing inclusive environments. For example, describing sensory qualities, which are mainly tacit by nature, is usually very difficult, nevertheless, they are decisive to make buildings more usable and enjoyable for all users by allowing a more fully multisensory experience [28].

Thus, whereas stated earlier that designers need genuine knowledge about user needs in order to make well considered design decisions, we in fact need to go one step further. In order to create inclusive environments, it will be of utmost importance that designers are able to develop tacit as well as explicit knowledge about user needs. Indeed, architects face a huge challenge to capture tacit as well as explicit types of user needs, to genuinely understand them and, moreover, to adequately translate them into design. However, a different approach is generally necessary when eliciting tacit user needs in contrast to explicit user needs and it is not always clear for designers how to manage this throughout the design process [15]. It is precisely this complex process of creating user knowledge by designers that we want to clarify and facilitate. In order to gain more insight into this user knowledge creation process, we propose to apply a model developed in KM, which we will describe next.

\section{SECI Model}

\subsection{Introducing the Model}

A theory regarding knowledge creation and conversion, originally developed by Nonaka [7], is generally known as the SECI model. Although it is not a recent model, it still proves to be very influential in its field of research and beyond [17, 29]. It was developed within the domain of KM, but since then it has also been used in various research domains to empirically and theoretically gain more insight in the nature of knowledge flows [30]. Here, we explore its potential to shed new light on how designers may create knowledge about user needs throughout UD processes. 
Originally developed to gain more insight in how organisations gain new knowledge and how this process may be managed more effectively, the model considers knowledge creation as a dynamic human process related to human action. This process is created through a "continuous dialogue between tacit and explicit knowledge" [7]. The interaction between tacit and explicit knowledge covers four different modes in which existing knowledge can be transformed into new knowledge [7]. They are identified in the SECI model as the modes socialisation (S), externalisation (E), combination (C) and internalisation (I).

$\begin{array}{lll}\text { Socialisation } & \rightarrow & \text { tacit knowledge to tacit knowledge } \\ \text { Externalisation } & \rightarrow & \begin{array}{l}\text { tacit knowledge to explicit knowledge } \\ \text { Combination }\end{array} \\ \text { Internalisation } & \rightarrow & \begin{array}{l}\text { explicit knowledge to explicit knowledge } \\ \text { explicit knowledge to tacit knowledge }\end{array}\end{array}$

Whereas the mode 'socialisation' focuses on converting tacit knowledge into tacit knowledge through shared experiences, 'externalisation' elicits explicit from tacit knowledge by creating a meaningful dialogue with users. The mode 'combination' exchanges and combines explicit knowledge and 'internalisation' converts explicit into tacit knowledge, which is addressed by Nonaka as a more traditional learning process. While each of the four modes can create knowledge independently, the model aims at visualising dynamic interaction between different modes of knowledge conversion [7]. Nonaka visualises this interaction as a linear process, more specifically as a spiral, involving all four modes subsequently. He differentiates multiple levels through which knowledge is created: from individual to inter-organisational level. All knowledge is first developed on an individual micro level in the minds of people before this knowledge can take form on a collective macro level. Clearly, it will be important for increasing the general uptake of UD that this knowledge is indeed becoming widespread throughout all these levels and it would be interesting to also take these levels into account. However, this paper will only focus on the individual, being the practicing architect, in the framework of a UD process.

\subsection{Knowledge Creation Theory within Design}

In the disciplines of art and design, the SECI model has already received some authors' attention for its interesting commonalities [e.g. 3, 4, 31, 32, 33], although it has not been explicitly used as an analytical framework in the domain of UD. Niedderer and Imani [4] have explored concepts of KM to "better understand and build research methodologies and to integrate individual methods with regard to managing different kinds of knowledge". They point out that the SECI model can indeed serve as an interesting framework to manage different kinds of knowledge in design research. Evenson and Dubberly [32] have also been inspired by the interesting link between KM and design and found similarities between models of design processes and the SECI model in terms of conceiving designing as a learning process. The SECI model is linked to, for example, IDEO models and Kumar's innovation model [32]. Indeed, the four modes of the SECI model display similarities with the steps in some design models. However, none of the existing design models elaborate on specific learning processes of designers in terms of creating tacit and explicit knowledge. We agree 
with Evenson and Dubberly [32] that the lens of the SECI model can potentially enrich our insights regarding the design discipline in general, but we will now focus more specifically on linking Nonaka's knowledge creation theory to a UD process.

\section{SECI Model for Universal Design}

In this section, we examine the SECI model more in detail from a UD perspective. When applying UD as a design strategy, it is fundamental to continuously consider user needs throughout the design process, as mentioned earlier. The SECI model may enable us to link knowledge about user needs to design knowledge. Moreover, the model distinguishes the transfer of tacit and explicit knowledge between source and receiver, i.e., user and designer, which, as was described earlier, is an important aspect of user needs. Four different modes can be distinguished in which designers develop knowledge in the process of trying to translate user needs into design solutions. In every mode designers can develop knowledge about user needs, but the approach or knowledge outcome may considerably differ. It is worth mentioning that the model emphasizes that it is the interaction between different modes that ultimately provides a rich source of tacit as well as explicit knowledge (in this case for designers throughout a UD process).

First, however, we need to consider the four modes separately in order to investigate their potential to better understand how knowledge can be created and how it may influence UD processes. Each mode is first described in terms of how architects may acquire knowledge in this mode. Additionally, the possible characteristics of knowledge are explained. Finally, suggestions are made about how this knowledge may affect the design process. Different examples within an architectural design process are used to illustrate these aspects in more detail.

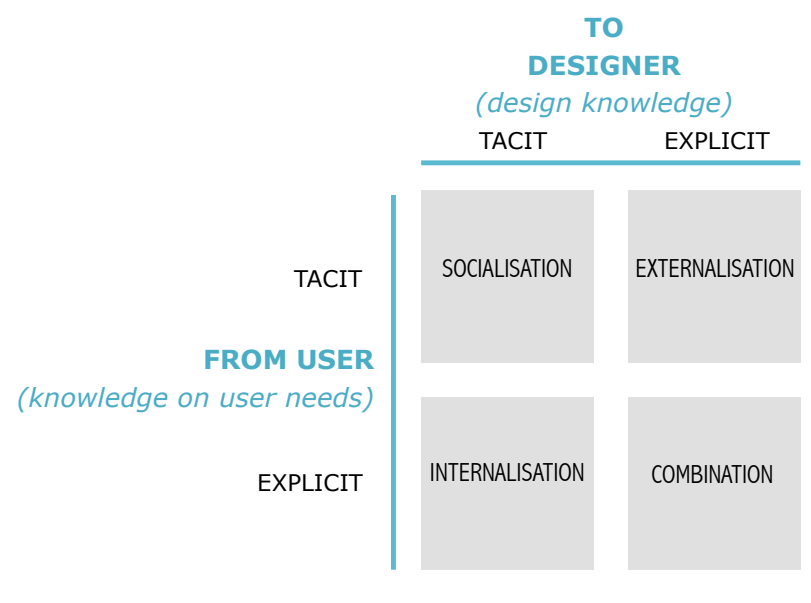

Fig. 1. SECI model for Universal Design 


\subsection{Socialisation from a UD Viewpoint: User Experiences}

The mode 'socialisation' represents the process of tacit knowledge (of users) converting into tacit knowledge (of the designer). Shared experiences are considered to be key when acquiring tacit knowledge [7]. For example, when designers need to design a new office building, they can develop knowledge by means of investigating time in open-ended observations of employees, their working habits, organisational culture, etc. Users are not always aware of their behaviour, actions or customs and this way, some user needs could be derived, even when not explicitly communicated beforehand or given a priori attention to by designers. These experiences on site may also give architects more insight in, for example, users' abilities. Instead of focussing on disabilities, as generally occurs, users' abilities may inspire designers when designing enabling environments [34]. These aspects are often easier to observe than verbally communicated. This knowledge does not only enable designers to get familiar with end-users and better understand their user needs, it may also generate empathy.

Apart from experiences on site, designers may also gain knowledge by means of their personal daily experiences or by, for example, participating in do-it-yourself workshops in which disabling situations are simulated. Although simulations do not serve as a complete substitute for users' experiences, they can give designers insights in how disabilities may affect people's daily lives. This way, understanding as well as empathy may be created among designers.

Based on the examples above, it is clear that these different experiences, whether or not linked to a specific project, may affect the design process in several ways.

Next to gaining insight in sometimes less apparent user needs, which designers may not been thinking of in the first place (e.g. observing people's abilities instead of focussing on their disabilities), 'socialisation' helps to gain empathy among designers. This may result in a more attentive design attitude towards user needs, positively influencing design decisions throughout the design process, without specifically articulating. Thus, 'socialisation' is not always intentionally created, neither is its origin always clear. Although the knowledge outcome for this mode may not always answer well-defined research questions, it may help designers to take well-founded design decisions throughout the design process.

\subsection{Externalisation from a UD Viewpoint: Meaningful Dialogue with Users}

A second mode called 'externalisation' focuses on the transformation of tacit knowledge to explicit knowledge. Interacting with users through meaningful dialogue, i.e., talking to users and genuinely listening to them, can reveal tacit user knowledge. For example, the architect of a school may have noticed that in the existing school one playground area is very popular, whereas another area remains unoccupied. When he or she confronts children with this observation, they cannot give a specific answer. In such a case, there might be underlying causes which nevertheless remain tacit: the organisation of the playground; its functionality; its atmosphere, etc. Still, it would be very interesting for the architect to have an insight in these underlying reasons in order to design a new playground. By asking questions in a more systematic way the designer might be able to find out why children like or dislike certain areas of the 
playground. This explicit knowledge may then be used to frame and create suited design solutions.

Nonaka and Konno [35] identify two key aspects to elicit tacit knowledge in the mode 'externalisation': (1) the use of specific techniques or methods to elicit this knowledge and (2) the translation of tacit knowledge into understandable forms. For example, highly specialised design language is not easy to understand by nonarchitects and therefore not interesting to employ when designers want to acquire knowledge from users. Similarly, design artefacts (e.g. sketches, models, CAD drawings, etc) need to be adapted when they are to be employed in conversation with users: not everyone can 'read' or 'fully understand' two-dimensional plans for example. "Architects probably design most frequently with the plan, which is a very poor representation of the experience of moving around in a building"[36]. Thus, when designers want to gain information from other people, they need to make sure that the (design) language as well as the (design) artefact is adapted to the people they want information from. However, design artefacts, when chosen well, are often used to stimulate interaction [37].

Thus, by creating a meaningful dialogue with users and genuinely listening to them, designers may elicit tacit user needs. The outcome for the mode "externalisation' is not supposed to be a list with requirements, but a deeper understanding of actions or underlying principles. This affects the design process in a way that it gives architects more insight in more complex why-or how-questions. In the example of the playground, users could not immediately answer the architect's questions. He or she needed to dig deeper and interact with people in a more systematic way in order to gain understanding in its underlying causes. Actively considering these why- and howquestions throughout the design process, understanding and adequately integrating them in design solutions, may improve the overall user experience of buildings.

\subsection{Combination from a UD Viewpoint: Q\&A about User Needs}

A third mode focuses on converting "explicit knowledge into more complex sets of explicit knowledge" [35]. Nonaka defines this process as 'combination'. Two groups can be identified in this mode. In the first group, explicit knowledge is created when designers communicate with different stakeholders in order to gain specific answers on specific questions. Whereas it is much more difficult in the mode 'externalisation' to elicit knowledge, here the answers are more easy to articulate. For example, specific surfaces to comfortably circulate in corridors or user needs already described in the design brief are situated in this mode. The second group consists of indirect ways to acquire knowledge about user needs, such as using checklists, guidelines or regulations. These are very explicit, generally directly related to a design, which makes them on the one hand time efficient, but on the other hand also less flexible, leaving not much room for designers' interpretation.

In sum, knowledge from the mode 'combination' affects the design process in such a way that it is very specific knowledge directly related and/or transferable to a design. This outcome is very interesting to rapidly gain knowledge about, for example, physical user needs, such as basic accessibility rules. However, it is much more difficult to make less specific user needs explicit, such as user needs facilitating personal growth [27]. Therefore, next to the interesting characteristics of knowledge created in 
the mode 'combination', it may not be applicable to all user needs leading to UD qualities, which are nonetheless necessary to create enabling and meaningful spaces.

\subsection{Internalisation from a UD Viewpoint: Learning-by-Doing}

The final mode 'internalisation' implies the process where explicit knowledge becomes tacit. Nonaka compares this to a more traditional learning process in which designers can learn-by-doing. By processing explicit knowledge through action, practice and/or reflection, it may really become knowledge of one's own [38]. For example, architects may learn from reading various books on UD. They may also learn from their own realised projects. Conducting a POE may help them to gain insight in how end-users experience the final design result. This way, knowledge can be generated for future projects by looking back at the level of inclusion of their own practice. This is learning-by-doing in its most obvious sense. Reflection-on-action [39] is fundamental in order to generate new tacit design knowledge [36].

In contrast to the other modes, it seems less evident to which extent the mode 'internalisation' affects UD processes. Learning-by-doing becomes the base for designers' new routines [32]. These developed routines are visible in the designer's actions and his or her design approach throughout the design process. Although this knowledge considerably contributes to improve the designer's UD strategy throughout the design process, their effects may be less recognisable for researchers. Thus, although in-depth UD knowledge can be acquired by combining knowledge from all four modes, knowledge developed in 'internalisation' as reflection-on-action is indispensable to embed UD as a design strategy into design processes.

\section{Discussion}

Four modes within the SECI model are viewed from a UD perspective, focussing on different ways in which designers can acquire knowledge about user needs. The examples given above may help to understand how every mode may be used when analysing designers' knowledge flow, however, looking at the examples from a slightly different perspective may shift them from one mode to another; For instance, in the example of the architect trying to find out why some areas of the playground remained unoccupied: if the children would have answered that, for example, a lack of benches was the main reason -and it turned out when examining this that it was indeed the true reason- the example would shift from 'externalisation' to 'combination'. Thus, all examples are influenced by specific circumstances, design approach as well as the designer's knowledge outcome. Nevertheless, this flexibility makes the models also very interesting to examine designers' highly dynamic and influential knowledge flows throughout UD processes.

Nonaka [7] argues that although "each of the four modes of knowledge conversion can create new knowledge independently, the central theme of the model [...] hinges on a dynamic interaction between the different modes." We agree that in-depth knowledge about user needs benefits from combining different modes. Although it has become clear that every mode has its specific positive characteristics, their 
strength lies in combining these modes. Creating knowledge by relying on one mode is not sufficient to capture tacit as well as explicit nature of user needs.

Nonaka visualises the interaction between the four modes as a spiral, involving each mode subsequently from socialisation to internalisation [7, 35]. When linking this spiral to different levels, from individual to organisational level, this structure may be applicable. However, when focussing on the individual knowledge creation process of the designer or design team, we assume that a more nuanced answer is necessary, tailored to the individual designer. The highly individual nature of the designer's knowledge creation process may not benefit from a specific order to follow when acquiring knowledge about user needs. The model's flexibility enables to use it in any direction without a prescribed route to follow.

Moreover, the model's abstract nature, i.e., dealing with communication flows, makes it possible to use it in different design situations as well as for different time periods. For example, it can be used to analyse small design projects of individual architects working for a single client as well as complex projects of a whole design team working with different stakeholders. When considering the time aspect, a specific design stage can be analysed as well as the whole design process. These levels are interchangeable using the same model, which makes it an interesting, dynamic tool for researchers to analyse UD processes.

In sum, the model shows potential in this context, but further research will of course be required to investigate the relevance of the model as an analytical framework, i.e., how useful it is to accurately and effectively describe daily UD design processes. For example, how do the four modes relate to each other within the designer's knowledge creation process in practice? Do designers follow all four modes of the model to create new knowledge or do they focus on some of them? Case studies where UD has been used as design strategy could enable researchers to gain more insight into these issues.

\section{Conclusion}

The challenging task of designers aiming at using UD as design strategy is to make appropriate translations of user needs into inclusive design solutions. As user needs are less tangible and most of its knowledge is tacit by nature, it is, however, very difficult to make them understandable to designers. Moreover, collecting information on user needs is not sufficient: Designers need to acquire knowledge by interpreting and genuinely understanding explicit as well as tacit user needs. Here, Nonaka's SECI model has been introduced as an interesting model to distinguish four ways for a designer to create knowledge about user needs. Every mode of the SECI model represents a different dialogue between tacit and explicit knowledge of user and designer. Whereas 'socialisation' focuses on understanding users through shared user experience, 'internalisation' learns-by-doing to create in-depth tacit knowledge about user needs. The mode 'externalisation' focuses on creating a meaningful dialogue with people and 'combination' gives specific answers on specific questions through direct as well as indirect user contact. From exploring how these processes might function in a UD context, we conclude that these different modes are indeed relevant and that every mode of the SECI model seems to affect the design process in a different way. 
From providing knowledge that is directly translatable into specific design parameters (combination) to creating empathy and providing insight in less apparent user needs that may not be articulated, but could be usable in different design decisions throughout the design process (socialisation). By introducing this model as an analytical framework to further investigate UD processes, we hope to achieve a better understanding of how designers create knowledge about user needs throughout the design process. This way, a more complete picture can allow us to optimise, stimulate and facilitate UD processes.

The final publication is available at Springer via http://dx.doi.org/10.1007/978-3-31941962-6

\section{References}

1. Dong, H., McGinley, C., Nickpour, F., Cifter, A. S., Inclusive Design Research Group: Designing for designers: Insights into the knowledge users of inclusive design. In: Applied Ergonomics. 46, pp. 284-291 (2015)

2. Herssens, J.: Design(ing) for more - towards a global design approach and local methods. In: Include Asia 2013 (2013)

3. Imani, Y.: Knowledge creation, business and art: exploring the contradictions and commonalities. In: Journal of Visual Art Practice. 6(2), pp. 141-153 (2007)

4. Niedderer, K., Imani, Y.: Developing a framework for managing tacit knowledge in research using knowledge management models. In: Undisciplined! Design Research Society Conference 2008 Sheffield Hallam University (2009)

5. Jensen, P. A.: Knowledge transfer from facilities management to building projects: A typology of transfer mechanisms. In: Architectural engineering and design management. 8(3), pp. 170-179 (2012)

6. Schindler, J.: Expertise and Tacit Knowledge in Artistic and Design Processes: Results of an ethnographic study. In: Journal of Research Practice. 11(2), (2015)

7. Nonaka, I.: A dynamic theory of organizational knowledge creation. In: Organization science. 5(1), pp. 14-37 (1994)

8. Herssens, J.: Universal Design: Een ontwerpstrategie met aandacht voor inclusie op micro, meso en macroschaal. Gent (2015)

9. Ielegems, E., Herssens, J., Vanrie, J.: A V-model for More. An inclusive design model supporting interaction between designer and user. In: Proceedings of the 20th International Conference on Engineering Design (ICED 2015) Design for life pp. 259-269 (2015)

10.Council of Europe: Achieving full participation through Universal Design. Resolution ResAP (2007)3 (2007)

11.Steinfeld, E., Tauke, B.: Universal Designing. In: Christophersen, J. (eds) Universal design: 17 ways of thinking and teaching. pp. 165-189 Husbanken (2002)

12.Kirkeby, I. M.: Accessible Knowledge-Knowledge on Accessibility. In: Journal of Civil Engineering and Architecture. (2015)

13.Steinfeld, E., Maisel, J.: Universal design: Creating inclusive environments. John Wiley \& Sons, Hoboken, New Jersey (2012)

14.Pemsel, S., Widén, K., Hansson, B.: Managing the needs of end-users in the design and delivery of construction projects. In: Facilities. 28(1/2), pp. 17-30 (2010) 
15.Goodman-Deane, J., Langdon, P. M., Clarkson, P. J., Clarke, S.: User involvement and user data: A framework to help designers to select appropriate methods. In: Langdon, P., Clarkson, J., Robinson, P. (eds) Designing Inclusive Futures. pp. 23-34 Springer, London (2008)

16.Bender, S., Fish, A.: The transfer of knowledge and the retention of expertise: the continuing need for global assignments. In: Journal of Knowledge Management. 4(2), pp. 125-137 (2000)

17.Liyanage, C., Elhag, T., Ballal, T., Li, Q.: Knowledge communication and translation-a knowledge transfer model. In: Journal of Knowledge Management. 13(3), pp. 118-131 (2009)

18.Court, A.: The relationship between information and personal knowledge in new product development. In: International journal of information management. 17(2), pp. 123-138 (1997)

19.Starbuck, W. H.: Learning by Knowledge-Intensive Firms. In: Journal of management studies. 29(6), pp. 713-740 (1992)

20.McGinley, C., Dong, H.: Designing with information and empathy: delivering human information to designers. In: The design journal. 14(2), pp. 187-206 (2011)

21.Woo, J.-H., Clayton, M. J., Johnson, R. E., Flores, B. E., Ellis, C.: Dynamic Knowledge Map: reusing experts' tacit knowledge in the AEC industry. In: Automation in construction. 13(2), pp. 203-207 (2004)

22.Froyen, H.: Universal Design, A Methodological Approach: A Pathway to Human-Friendly and Elegant Architecture. Institute for Human Centered Design, Portland, Boston (2012)

23.Nickpour, F.: Public engagement with inclusive design: a platform for co-design with people. In: Design for All. 5(6), pp. 26-35 (2010)

24.Maslow, A. H., Lewis, K. J.: Maslow's hierarchy of needs. Salenger Incorporated (1987)

25.Polanyi, M.: The tacit dimension. The University of Chicago Press, London (1967)

26.Nimkulrat, N., Niedderer, K., Evans, M.: On Understanding Expertise, Connoisseurship, and Experiential Knowledge in Professional Practice. (2016)

27.O'Shea, E. C., Pavia, S., Dyer, M., Craddock, G., Murphy, N.: Measuring the design of empathetic buildings: a review of universal design evaluation methods. In: Disability and Rehabilitation: Assistive Technology. 11(1), pp. 13-21 (2014)

28.Herssens, J.: Designing for more: a framework of haptic design parameters with the help of people born blind. University of Hasselt - Leuven, University of Hasselt - Leuven (2011)

29.Teece, D. J.: Nonaka's Contribution to the Understanding of Knowledge Creation, Codification and Capture. In: Towards Organizational Knowledge: The Pioneering Work of Ikujiro Nonaka. pp. 17-23 (2013)

30.Nonaka, I., Von Krogh, G.: Perspective-tacit knowledge and knowledge conversion: Controversy and advancement in organizational knowledge creation theory. In: Organization science. 20(3), pp. 635-652 (2009)

31.Manhães, M., Varvakis, G.: Designing services as a knowledge creation process: Integrating the double diamond process and the SECI spiral. Touchpoint (2010)

32.Evenson, S., Dubberly, H.: Design as learning - or "knowledge creation"-the SECI model. In: Interactions Magazine. 18(2), pp. 1-6 (2011)

33.Kieslinger, B., Pata, K., Fabian, C. M.: A Participatory Design Approach for the Support of Collaborative Learning and Knowledge Building in Networked Organizations. In: International Journal of Advanced Corporate Learning (iJAC). 2(3), pp. 34-38 (2009)

34.Keates, S., Clarkson, J., Harrison, L.-A.: Towards a practical inclusive design approach. . In: CUU'00 conference on Universal Usability ACM (2000)

35.Nonaka, I., Konno, N.: The concept of "ba": Building a foundation for knowledge creation. In: California management review. 40(3), pp. 40-54 (1998)

36.Lawson, B.: How designers think. The Design Process Demystified. Architectural Press, London (2005) 
37.Perry, M., Sanderson, D.: Coordinating joint design work: the role of communication and artefacts. In: Design Studies. 19(3), pp. 273-288 (1998)

38.Nonaka, I., Toyama, R., Konno, N.: SECI, Ba and leadership: a unified model of dynamic knowledge creation. In: Long range planning. 33(1), pp. 5-34 (2000)

39.Schön, D. A.: Educating the reflective practitioner. (1987) 